\title{
Utilização de plataformas interativas e novas tecnologias no ensino de física das radiações para cursos da área de saúde
}

Use of interactive platforms and new technologies in the radiation physics teaching for health area courses

\author{
Teresa Cristina dos Santos Leal ${ }^{*}\left[0\right.$, Alaercio Aparecido de Oliveira ${ }^{2}$ \\ ${ }^{1}$ Faculdade Inspirar, Núcleo de Ensino e Pesquisa, Curitiba, PR, Brasil \\ ${ }^{2}$ Faculdade Inspirar, Núcleo de Tecnologia Social, Curitiba, PR, Brasil
}

\begin{abstract}
Recebido em 20 de Dezembro, 2018. Revisado em 21 de Fevereiro, 2019. Aceito em 28 de Fevereiro, 2019.
O presente artigo apresenta a dificuldade que discentes das áreas de saúde encontram na compreensão de conceitos de Física das Radiações e sua aplicabilidade. A utilização de ferramentas e métodos inovadores e tecnológicos associados aos conceitos teóricos favorece o ensino-aprendizagem. A pesquisa descreve resultados que retratam mudanças que são percebidas nos estudantes durante e após a utilização das ferramentas e demonstram a posição do estudante como sujeito ativo no processo de ensino-aprendizagem. A partir de um movimento de transformação das estruturas disciplinares, evidencia-se a correlação entre a busca de maior participação ativa e crítica dos estudantes quando se tem um dinamismo nas aulas. Conclui-se que as vantagens em termos de aproveitamento, desempenho académico e satisfação dos estudantes envolvidos quando comparado com os métodos tradicionais de ensino, foi de aproximadamente $93 \%$ de aceitação, o que expressa um aumento significativo no desempenho dos alunos e a boa aceitação de tais metodologias. Verifica-se também a satisfação do professor, que passa a estimular mais seus alunos, a exercer diversas atividades mentais dos discentes em novas proposta, oportunizando que estes assimilarem e construíam novos conhecimentos, desenvolvendo o raciocínio crítico.
\end{abstract}

Palavras-chave: Física das radiações aprendizagem significative, novas tecnologias.

\begin{abstract}
The research presents the difficulty that students of the health areas face to understanding concepts of Radiation Physics and their applicability. The use of innovative and technological tools and methods associated with theoretical concepts favors the teaching learning process. The research describes results that show changes that are perceived in students during and after the use of the tools and demonstrate the student's position as an active subject in the teaching learning process. From a movement of transformation of the disciplinary structures, it is evident the correlation between the search of greater active and critical participation of the students when one has a dynamism in the classes. It was concluded that the advantages in terms of achievement, academic performance and student satisfaction involved when compared to traditional teaching methods were approximately 93\% acceptance, which expresses a significant increase in students' performance and the good acceptance of such methodologies. It is also verified the satisfaction of the teacher, who begins to stimulate more students, to exercise several mental activities of the students in new proposals, allowing them to assimilate and build new knowledge, developing critical thinking.
\end{abstract}

Keywords: Radiation physics, meaningful learning, new technologies.

\section{Introdução}

Os conteúdos de Física são o pesadelo da grande maioria dos acadêmicos. As disciplinas de matemática e física, trazem resistência e rejeição aos conteúdos em geral. Essa postura não é diferente nos cursos de ensino superior da área da saúde, onde há relatos de docentes e discentes sobre a dificuldade no processo de ensino-aprendizagem.

As disciplinas com base na Física têm um grande número de desistentes ou reprovações em cursos superiores, o que tem sido um grande desafio para os professores a buscarem novas metodologias que sejam mais atraentes e envolventes para o aluno. Denota barreiras elevadas por

*Endereço de correspondência: teresa.s.leal@gmail.com anos de ensino sem atrativos e repetitivo desde o ensino fundamental que se arrasta até o ensino médio, levando o aluno a não perceber os desafios e as estratégias do conteúdo a ser estudado com sua vida profissional o que o coloca de forma passiva e distante. Isso é reforçado ainda pela postura de certos professores que não querem se adaptar e continuam a lecionar de forma clássica e tradicional sem dar importância às dificuldades apresentadas pela maioria dos alunos, principalmente em se tratando de Física das Radiações [1,2].

Assim, a mudança de postura visando uma educação menos pragmática e mais crítica aparece como pano de fundo enfatizado em alguns trabalhos; no entanto, poucos explicitam tais dimensões [3]. O processo de mudança é longo e deve estar baseado em uma nova relação entre 
ciência e sociedade e também na tecnologia e na inovação. Essa mudança só poderá existir se todos os cidadãos possuírem formação e cultura científica que lhes permitam compreender e administrar sua vida cotidiana, enfrentálas e integrar-se a ela de maneira crítica e autônoma, estando capacitados a tomar decisões [4].

O enfrentamento destes paradigmas é fundamental para a compreensão do ensino da física das radiações a que se destina tal pesquisa. Este estudo visa refletir uma relação dialética entre os saberes e a realidade envolvendo a práxis existente, o ideal e o dinâmico, para propor uma análise sobre os conceitos envolvidos e discutir a construção de um saber enraizado no conteúdo e em práticas inovadoras de forma que possa propiciar ao aluno um ambiente acolhedor e prazeroso através de práticas que possam evidenciar possibilidades, como jogos e atividades que façam parte da dinâmica do saber aprender a fazer participando, porque possibilita a interação, a integração à incorporação gradativa do conhecimento. Para tal, objetiva-se aplicar o uso de plataformas interativas e atividades o que permitirá ao próprio aluno relacionar o conceito teórico com a prática.

\subsection{Física nuclear no Brasil}

Um dos precursores da pesquisa científica na área da Física no Brasil foi o físico ucraniano Gleb Wataghin. Wataghin ingressou na USP em 1934, onde iniciou suas pesquisas sobre raios cósmicos e sobre Física Nuclear. Na época, investia-se pouco nesse tipo de pesquisa, então, os primeiros instrumentos necessários para o estudo da Física Nuclear foram construídos pelos alunos da primeira turma de Física daquela universidade: Marcelo Damy e Oscar Sala. A partir dessa época, a pesquisa em Física Nuclear no Brasil cresceu até atingir visibilidade internacional [5].

\subsection{Física das radiações e a saúde}

A Física Nuclear estuda os fenômenos físicos relativos os núcleos atômicos, como transições de energia, decaimentos radioativos, fissão e fusão nuclear, entre outros. O estudo da Física Nuclear faz parte da componente curricular de alguns cursos da área de saúde e a sua compreensão envolve modelos fundamentais para a aprendizagem do funcionamento dos núcleos atômicos e sua constituição, aplicações da energia nuclear em tratamentos médicos, estudo de tecnologias para detecção de radiação, novas fontes de energia, etc.

É fato que nos últimos anos, a Física Nuclear teve desenvolvimentos importantes na área da saúde humana, por meio da medicina nuclear com o surgimento de tecnologias de grande impacto na saúde [6]. Um crescente número de exames de imagem tem sido realizado com uso de diferentes tipos de radiação e partículas, o que também traz complicações como afirma Dondi [7], devido à inexistência de um guia que oriente as práticas e procedimentos nucleares em medicina, o que viria a facilitar a qualidade do serviço e a segurança do paciente. Um grande número de pacientes recebe tratamento oncológico por meio da radiação produzida por aceleradores de partículas ou fontes naturais de radiação, como o césio-137, que é um isótopo radioativo (radioisótopo do elemento químico Césio), o iodo-131, outro radioisótopo muito usado no tratamento de câncer de tiroide, entre outros amplamente utilizados na medicina nuclear. Atualmente existem vários tratamentos avançados de câncer, com menos efeitos colaterais, que são capazes de destruir os tecidos afetados pelo câncer por meio da emissão prótons, nêutrons, íons pesados e radiação eletromagnética ionizante.

\subsection{Uso da tecnologias da informação no ensino}

Inovação e tecnologia, se vivenciará segundo Costa [8] como sendo a $4^{\mathrm{a}}$ revolução industrial, onde o "BUMMM" tecnológico incessante se estende por una maré de informações disponíveis que se atualizam a todo o momento. $\mathrm{O}$ ensino/aprendizagem navega na mesma velocidade e as pessoas querem o conhecimento, mas na mesma frequência que suas informações estejam disponíveis em apenas um click, o anseio pelo novo e por novas formas de mediar o conhecimento tornou-se prioridade em todas as Instituições de Ensino Superior. Com o ensino de física não é diferente; não existe mais espaço para a aula tradicional, necessita-se de formas atuais tecnológicas para melhores práticas e melhor transição no processo do "saber".

As Tecnologias de Informação e Comunicação, TICs, podem trazer soluções inovadoras, que assumem um papel preponderante nas aulas práticas, que normalmente são muito interessantes para os alunos, mas por sua vez demanda tempo de preparo, equipamentos e o espaço apropriado de um laboratório. Os recursos tecnológicos como dispositivos móveis: os smartphones e tablets, as TICs não demandam a constituição de um laboratório específico para sua utilização, tornando-se uma alternativa de baixo custo, além de ser mais atraente para o aluno, que já faz uso dessa ferramenta tecnológica em sua vida cotidiana.

A utilização TICs como uma ferramenta é capaz de propiciar uma aproximação mais efetiva entre os discentes e docentes como está previsto nas Diretrizes Curriculares Nacional (DCN) na área de saúde [9] e traz estas reflexões relacionando a importância conceitual do conhecimento com a tecnologia construindo então um diálogo entre as dimensões do conhecimento, o desenvolvimento tecnológico e as perspectivas do próprio aluno. Segundo Carvalho [10], o acesso às tecnologias da informação e comunicação está relacionado com os direitos básicos de liberdade e de expressão, portanto os recursos tecnológicos são as ferramentas contributivas ao desenvolvimento social, econômico, cultural e intelectual. A Lei de Diretrizes e Bases 9394/96 da educação nacional, propõe uma prática educacional adequada à realidade do mundo, ao mercado de trabalho e à integração do conhecimento [11]. 


\subsection{O uso de gamificação}

Com todas as possibilidades tecnológicas disponíveis no mercado globalizado o uso de jogos é o que mais fomenta a curiosidade, o interesse e desafios aos jovens e adultos, e notadamente de forma surpreendente novos adeptos para as empresas e de igual modo se estabelecerá na seara acadêmica, intitulada como, "gamificação". Sheldon [12] define que a gamificação como a aplicação de mecânicas de games a atividades que não são de games". Essa metodologia não é o ensinar por meio de jogos, pois hoje a maioria das instituições já o fazem, mas sim utilizar elementos dos games como forma de promover a motivação e o envolvimento dos educandos. Assim, verifica-se que os games podem ser usados para solucionar problemas complexos do mundo sensorial, causal e real do saber a aprender, para desenvolver as habilidades como pensamento crítico, resolução criativa de problemas e trabalho em grupo, podendo gerar surpreendentes soluções que o ensino tradicional enfrenta como desafios.

\section{Material e métodos}

Esta pesquisa intenciona caracterizar o "estado do conhecimento", que segundo Morosini, [13], é quando se identifica, registra e categoriza de forma sintética a produção científica existente em uma determinada área, em determinado espaço definido segundo a necessidade e propósitos do pesquisador. Assim, o enfoque está voltado para a aprendizagem baseada em problemas, sua aplicação prática especificamente às medidas táticas relacionadas aos objetivos de ensino, integração da física da radiação com saberes básicos no campo da saúde, boa qualidade metodológica e validade de suas conclusões.

$\mathrm{Na}$ primeira etapa da pesquisa foi realizada uma busca textual ao tema e as dificuldades relacionadas ao conteúdo. Segundo o autor Marconi [14], esta etapa também pode ser considerada como exploratória, pois visa responder, dar uma hipótese para o problema pesquisado, bem como clarificar conceitos. Marcada também por uma abordagem quantitativa e qualitativa, que diferem entre si em relação à sua natureza, do ponto de vista metodológico, elas não se opõem, assim como não há linearidade, entre investigação de ambas. A pesquisa quantitativa atua em níveis de realidade e tem como objetivo trazer resultados através de indicadores e outras técnicas estatísticas. A investigação qualitativa, ao contrário, trabalha com valores, crenças, representações, hábitos, atitudes e opiniões [15]. Ambas possuem suas importâncias nas pesquisas científicas atuais.

A segunda etapa se concretizou através de um estudo de caso, conforme sugere Yin [16], essa apresenta uma estratégia de pesquisa que compreende um método completo para abordagens específicas de coletas e análise de dados, onde pode-se enfatizar a abordagem do problema de forma qualitativa e quantitativa. Assim, os instrumentos de coleta de dados utilizados foram a observação e um questionário online com perguntas fechadas, elaborado pela própria autora da pesquisa com o uso da ferramenta do Google Docs [17], destinado a uma turma, onde o professor adotou a utilização de plataforma interativa, vídeos e simuladores afim de verificar a evolução do ensino/aprendizagem após a abordagem pelo professor.

Os temas foram escolhidos de acordo com o conteúdo da disciplina de Física das Radiações na turma, entre aqueles descrito pelo professor, que vinham apresentando uma maior resistência na aprendizagem por parte dos alunos, sendo estes os conteúdos relacionados a Interação da Radiação, em particular sobre o efeito fotoelétrico.

\subsection{A seleção dos aplicativos}

Com a popularização dos tablets e smartphones procurouse por aplicativos Android, gratuitos, que poderiam ser utilizados tanto em classe como em qualquer lugar onde o aluno levasse seu dispositivo móvel. Como atualmente é o celular, o artefato tecnológico e de uso cotidiano dos alunos este é o mais indicado para ser utilizado também numa ferramenta de ensino e aprendizagem. A opção pelo sistema Android foi porque a maior parte dos alunos utilizam aparelhos com esse sistema. Não foi verificado a existência de apps em português para que os alunos pudessem utilizar em sala sobre o assunto, porém foi encontrado um especificamente para o assunto, que apresentou ser uma ótima opção para simulação que é o PHET Interative Simulation [18].

Foi selecionado uma turma com trinta (30) alunos do curso superior de tecnologia em radiologia do segundo $\left(2^{\circ}\right)$ período, curso noturno, de uma Instituição de Ensino Superior (IES) do Paraná.

Primeiramente o professor disponibilizou na plataforma do ensino da IES, o material de apoio (com uma semana que antecede a aula para aprendizagem do conteúdo), para avaliação previa do aluno, sendo uma apostila sobre o tema e um vídeo informativo sobre o assunto. Assim, o aluno tem como se antecipar ao conteúdo e pode acessa-lo em qualquer lugar e estudar o seu conteúdo. No dia da aula o professor pediu para os alunos que formulassem hipóteses sobre o que leram e desta forma analisassem os mapas conceituais do assunto. Nesta primeira etapa verificou que mais de $30 \%$ dos alunos não entenderam bem o vídeo e o material fornecido. O professor então dividiu a turma em equipes de tal forma que interagissem entre eles e vissem o vídeo novamente. Após alguns debates entre eles, o professor pediu que utilizassem a plataforma PHET no link https://phet.colorado.edu/ pt_BR/simulation/photoelectric e verificasse exatamente o que ocorre em materiais diferentes. A Figura 1 ilustra exatamente o momento o efeito fotoelétrico, visto pelos alunos.

Os estudantes não conheciam ainda a plataforma mais rapidamente dominaram seu uso e fizeram várias simulações, comentando e anotando as possibilidades. Finalizada a aula o professor pediu para que todos guardassem 


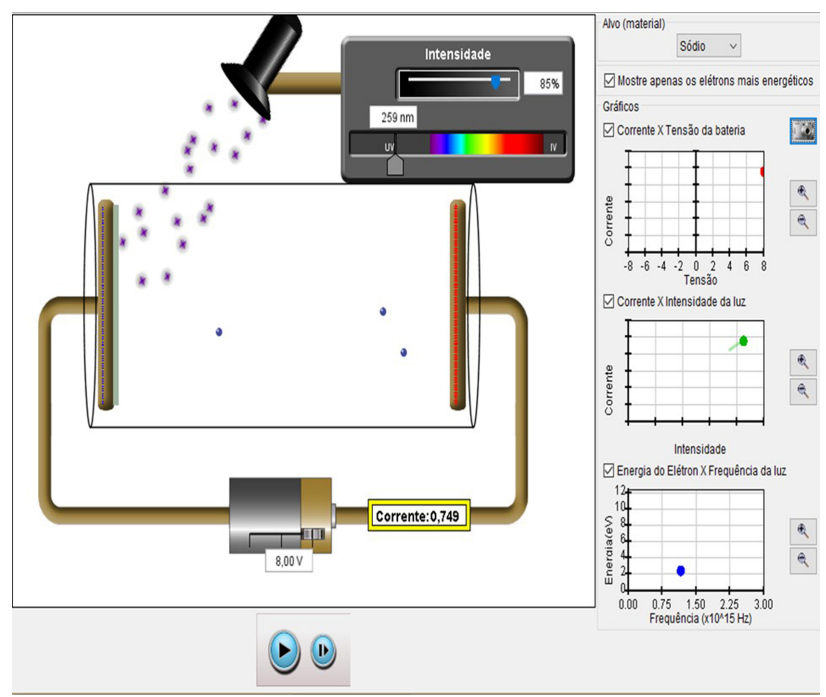

Figura 1: Efeito fotoelétrico (alvo: sódio). Fonte: Apps PHET Interactive Simulation (2018 University of Colorado).

suas anotações e trouxessem o celular para utilizar a plataforma de ensino da IES, onde está disponível o material de apoio para a próxima aula, pois iriam novamente ser utilizado para o término do conteúdo.

Para a aula seguinte foi utilizado o aplicativo Plickers[19], que possibilita ao professor fazer uma análise dos conceitos apreendidos pelos alunos até aquele momento, o que precisa apenas de um computador ou notebook, um projetor e um dispositivo móvel (smartphone ou tablet). Este aplicativo permite que o professor aplique questões com quatro opções de respostas e aplique em suas turmas, com os respectivos nomes dos alunos, podendo assim saber quais os alunos estão com maior dificuldade em determinado assunto trabalhado em sala. Para isso é necessário que o professor baixe da página do Plickers as fichas que contém as opções de respostas de A a D, denominadas de QRcodes, e imprima de acordo com o número de alunos da turma. Antes de aplicar é necessário cadastrar as questões no aplicativo com as suas respectivas respostas. Ao fotografar a turma com os cartões o aplicativo identifica os cartões e fornece a estatística das respostas, o que é feito com o celular do professor, e é mostrado automaticamente na tela de projeção ou TV, para todos os alunos.

$\mathrm{Na}$ aula seguinte foi feito então o uso da Gamificação, como tecnologia ativa, usando a plataforma Plickers. O professor montou 20 questões sobre a temática, cadastra a turma e pode se preferir seus nomes. A turma se mantêm motivada, pela competição e por esta dinamizando o conteúdo já visto e aprendido na aula anterior.

As respostas dos alunos em QRcodes (cartão de resposta dos alunos com as opções de respostas as questões), ilustrado na Figura 2 são lidas pelo celular do professor. O professor seleciona a opção "live view" na página web do aplicativo, seleciona posteriormente na versão móvel qual questão deseja exibir, a questão é então exibida na

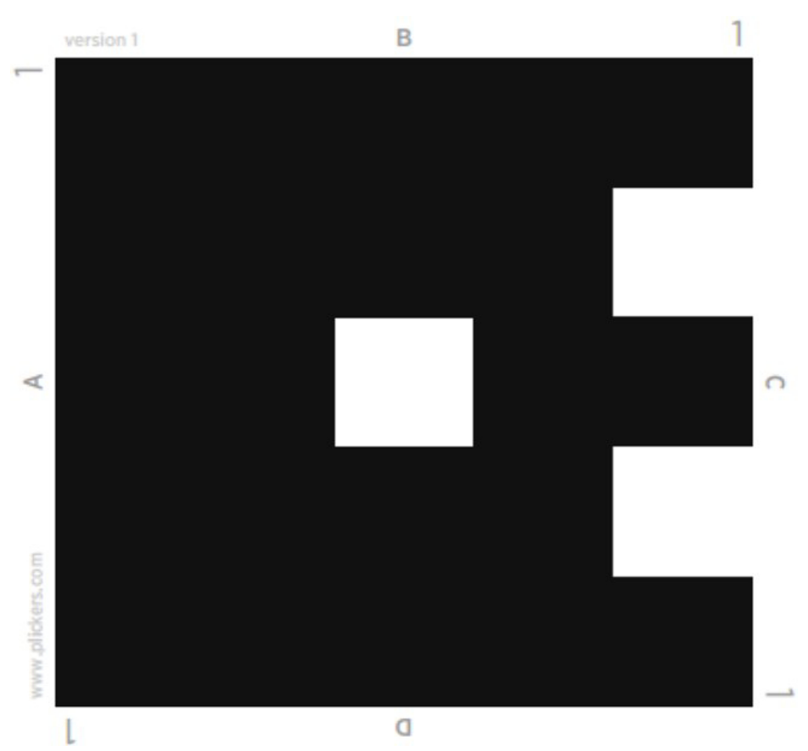

Figura 2: Exemplo de cartão resposta do Plickers - QRcodes. Fonte: Plickers.

tela do computador do professor, conforme exibido na Figura 3.

Cada estudante exibe seu cartão indicando a resposta que julga adequada para a questão. O professor, no aplicativo, habilita a câmera para leitura dos códigos dos cartões e instantaneamente o aplicativo obtém as respostas de cada aluno, atribuindo certo ou errado.

Ao final da aula o professor apresenta a estatística de cada aluno, apresentando os seus pontos fortes e gráficos de acertos, pode se apresentar a aluno que mais pontuou. Este ganha o passe de monitoração dos alunos até o próximo conteúdo para auxiliar outros alunos.

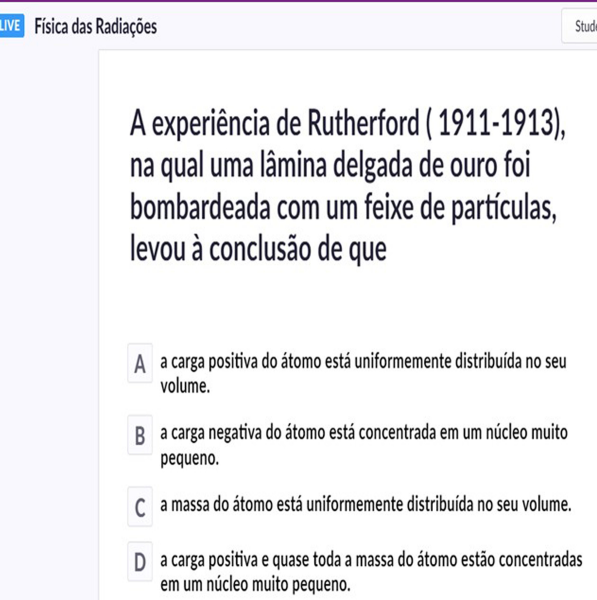

Figura 3: Telas do aplicativo Plickers em execução. Fonte: https://www.plickers.com/ 


\section{Resultados e discussão}

Após a finalização deste conteúdo, passou-se a análise dos dados coletados e os resultados obtidos através da aplicação dos questionários pelos alunos, que fizeram uso o aplicativo Plickers, PHET e o vídeos informativos utilizados na plataforma da IES.

Observa-se que o professor fez uso do Peer Instruction, na primeira aula dada após ter colocado o material de apoio prévio disponível na plataforma de acesso aos alunos na IES. Estes puderam acessar, ler e estudar o conteúdo fora do ambiente de sala de aula de tal forma a já ir para sala com suas dúvidas formuladas e concepções sobre o material disponível. Pela interatividade entre os participantes, na aula seguinte, bem como a exigência dos estudantes se tornarem corresponsáveis naquele momento pelo sucesso da sua aprendizagem - a aprendizagem ativa, na forma como em equipes interagiram. Os colegas passando seus conhecimentos e quebrando paradigmas, essa metodologia a Peer Instruction (PI) foi desenvolvida no início dos anos de 1990 pelo professor Eric Mazur, na Universidade de Harvard (EUA) [20], que traz a relação de tecnologias, por exemplo os aparelhos celulares e smartphones, TVs como ferramentas para mediar as práticas pedagógicas tendo potencial para despertar o interesse e a atenção dos alunos, fortalecendo o ensino e a aprendizagem [21].

A junção das metodologias aplicadas, a Peer Instrution (PI) e a gamificação (Aprendizagem Baseada em Times) resultou em um total de $90 \%$ de compreensão do conteúdo por parte dos alunos. Os que apresentaram um percentual menor foi de $75 \%$ de compreensão, o que trouxe à turma uma nova perspectiva do assunto ao contrário da forma tradicional de aprendizagem de tal tema.

Neste momento foi então aplicado um questionário Google Formulário para que os alunos respondessem o que acharam da metodologia aplicada e sobre compreensão dos conteúdos da disciplina. Este composto apenas de quatro perguntas sobre o material prévio e vídeos adicionados na plataforma da IES, sobre a plataforma PHET e sobre o uso da plataforma Plickers e a última sobre o que acharam sobre a metodologia aplicada pelo professor na disciplina, conforme ilustram as Figura 4 à Figura 7 abaixo. Na Figura 6 observa-se ter uma resposta a menos, ou este esqueceu de responder à pergunta ou absteve-se em respondê-la.

Observa-se que a metodologia aplicada pelo professor teve um índice a 93,3\% de aceitação pra ótimo pelos alunos, as plataformas interativas resultaram no dinamismo da aula potencializando a assimilação do conteúdo e a aceitação por parte dos alunos onde $100 \%$ dos alunos gostaram da interação e sobre a disponibilidade de acesso aos conteúdos prévios na plataforma da IES quase que $80 \%$ concluíram que o material favorecia a aprendizagem.

Logo a utilização dos aplicativo Plickers e PHET podem auxiliar no desenvolvimento e apoio à avaliação formativa de maneira dinâmica e estimulante ao aluno, conforme utilizado no presente estudo.

\section{Conclusão}

As frequentes dificuldades na aprendizagem de conteúdos de Física das radiações por parte de estudantes em geral e das áreas de saúde em particular, levaram à necessidade de estabelecer estratégias de ensino baseada no uso das TICs, nomeadamente para tal estudo se baseou na

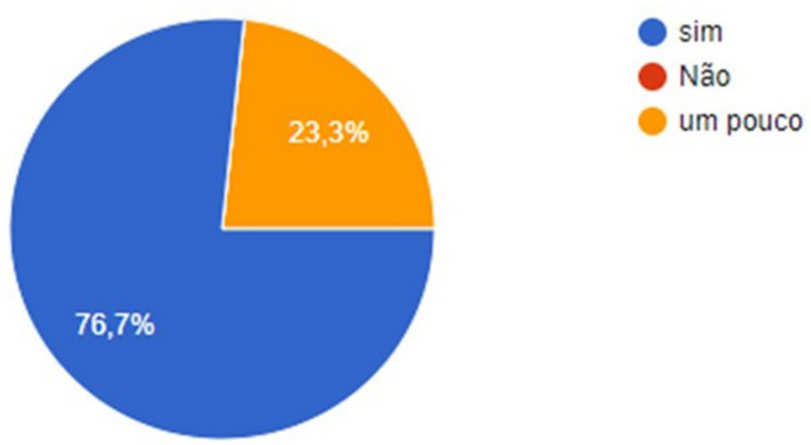

Figura 4: Pergunta 1: Você acha que o vídeo disponibilizado pelo professor previamente na plataforma de acesso da IES, é esclarecedor sobre o tema abordado? Fonte: Própria, 2018.

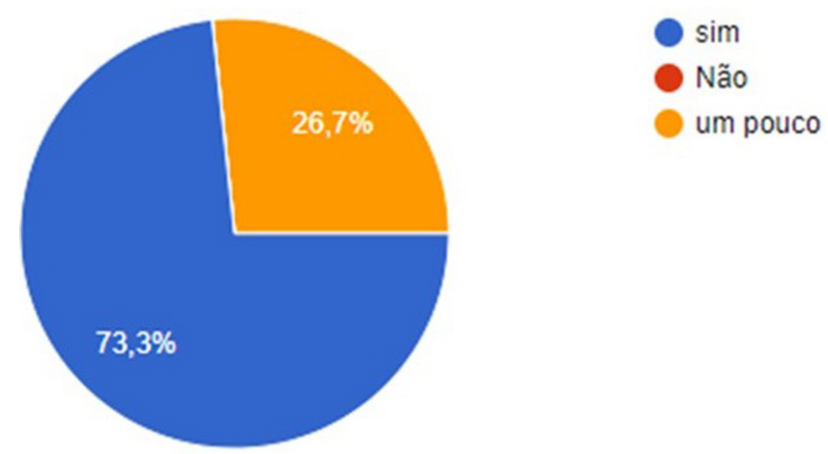

Figura 5: Pergunta 2: Você acha que o material disponibilizado pelo professor previamente na plataforma de acesso da IES, foi esclarecedor sobre o tema abordado? Fonte: Própria, 2018.
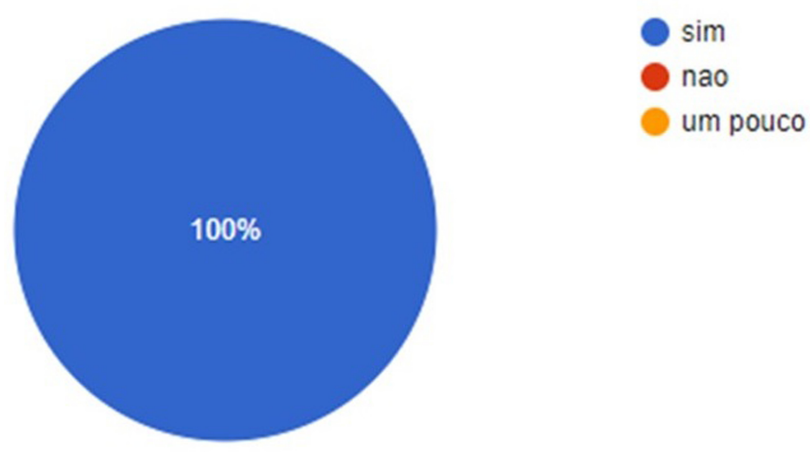

Figura 6: Pergunta 3: Você gostou da utilização da plataforma PHET e do uso da plataforma Plickersna inserção de conteúdo disponibilizado pelo professor? Fonte: Própria, 2018. 


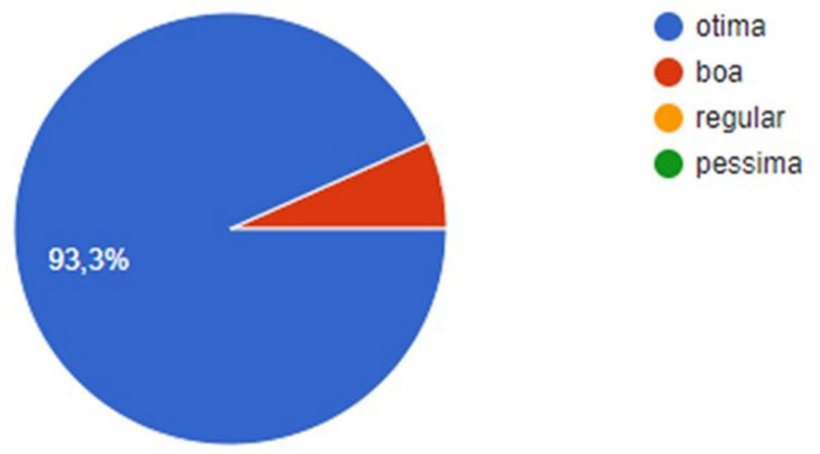

Figura 7: Pergunta 4: Você gostou da forma proposta pelo professor na apresentação do conteúdo sobre Física das Radiações? Fonte: Própria, 2018.

plataforma de uso da própria IES que disponibilizou material prévio dos conteúdos a serem estudados e o uso das ferramentas da web 2.0, tais como a plataforma Plickers e a plataforma PHET, numa visão inovadora, motivadora e promissora para que os alunos tomassem consciência das suas limitações nas aprendizagens tradicionais ao longo dos diversos conteúdos, lecionados na disciplina de Física das radiações. No caso concreto desta investigação, aprender com o feedback através de novas ferramentas, desenvolvido no contexto sala de aula.

Neste trabalho o estudo foi direcionado a uma turma, com 30 alunos do segundo período do curso superior de tecnologia em radiologia. Utilizou-se como instrumentos de coleta de dados, um questionário, com questões da ferramenta Plickers e o PHET. O principal objetivo do estudo foi identificar possibilidades de utilização das ferramentas Plickers e a PHET para facilitar e/ou melhorar a avaliação tanto diagnóstica como formativa.

Em relação à avaliação diagnóstica, a ferramenta Plickers demonstrou ser uma ferramenta fácil, rápida e eficaz tanto para os alunos, como para os professores pois ambos têm acesso aos resultados, permitindo que os professores consigam verificar os pré-requisitos dos alunos e que os alunos detectam de onde precisam de maior compreensão ou estudo.

Para a avaliação formativa, ambas as plataformas se mostram eficientes para as metodologias escolhidas. Procurava-se uma ferramenta que facilitasse a apresentação do conteúdo, que tivesse um designer estimulante ao aluno e que oferecesse uma possibilidade rápida de captação de dados nas atividades propostas pelo professor. Nestes itens a plataforma PHET, foi utilizada, sendo um pouco mais trabalhosa o seu manuseio pelos alunos, porém após explicação do professor quanto ao seu uso, os alunos dominaram perfeitamente as atividades, conseguindo as habilidades para o término da proposta com êxito. A plataforma Plickers também foi utilizada neste momento, com base na metodologia de gamaficação, onde os alunos demonstraram entusiasmo e conhecimento do conteúdo já previamente analisado por eles. Em relação à avaliação formativa, a ferramenta Plickers facilita, na autoavaliação. Os dados sugerem que o método de aprendizagem utilizado proporciona aos alunos um feedback para que estes tivessem consciência de quais eram as suas dificuldades no saber aprender, permitindo assim melhorar a aprendizagem. Assim, existem evidências de que 28 alunos melhoraram a sua aprendizagem, tendo como, referência os erros realizados na avaliação formativa, através da ferramenta Plickers e os acertos de forma significativa do saber a aprender a aprender com tecnologias.

Usando o Plickers, também foi possível detectar que dois alunos tiveram uma dificuldade inicial com o material prévio fornecido pela plataforma da IES, nos dois instrumentos de avaliação cuja finalidade é estimular a autoaprendizagem, o que permitiu ao professor uma atenção maior a estes alunos.

Outro ponto observado pelo docente foi a maior autonomia dos alunos. Estes conseguiram avançar no desenvolvimento das competências da disciplina e identificar os pontos em que apresentaram dificuldades anteriormente, tendo a disciplina nenhum índice de evasão, o que surpreendeu quando comparado aos semestres anteriores. Os resultados obtidos sugerem que o uso das ferramentas PHET e Plickers facilitou as estratégias de avaliação, devido ao dinamismo da aula e ao feedback que essas ferramentas oferecem na melhoraria da aprendizagem.

Observa-se ainda, baseado nos objetivos previamente determinados, que a utilização da tecnologia associada à prática pedagógica, principalmente na avaliação, produz resultados relevantes tanto para alunos quanto para professores. Para os alunos, por reduzir a ansiedade, diminuir o acúmulo de matéria e utilizar tecnologias às quais os mesmos estão habituados a utilizar em seu cotidiano e para os professores por servir como instrumento de melhoria da avaliação de alunos e da própria prática didática, tornando possível para o mesmo visualizar que conteúdos ministrados não foram bem absorvidos pelos alunos, melhorando o processo ensino-aprendizagem e aumentando a atenção e interesse dos alunos por este conteúdo.

\section{Referências}

[1] L.V.S. Garcia, A física moderna e contemporânea no ensino médio: caminhos para a sala de aula. Dissertação de Mestrado, Universidade de São Paulo, São Paulo (2009).

[2] H. Shiino, G. Watanabe, C.M. Rizzatto e G. WatanabeCaramello, in IX Encontro Nacional de Pesquisa em Educação em Ciências (Águas de Lindóia, São Paulo, 2013).

[3] B. Macedo e R. Katzkowicz, Educação científica: sim, mas qual e como? (Unesco, Brasília, 2003), p. 67.

[4] A. Tenório, L.S. Quintana, W.V. Nunes e T. Tenório, Revista Electrónica de Enseñanza de las Ciencias 14, 175 (2015).

[5] M.M. Gobato, Inovações em propostas de formação docente: um estudo sobre as Licenciaturas em Ciências da Natureza de universidades públicas brasileiras. Disserta- 
ção Pós-Graduação, Universidade Estadual de Campinas, Campinas (2018).

[6] T.T.A. Kubo, R. Biancardi, A.M.G. Rocha, D.R. Ferreira, F.A.A. Silva, J.B.A. Assunção, E.H. Alves, A.F.B. Almeida, N.F. Alves, F.H.Z. Xavier et al., Revista Brasileira de Física Médica 11, 35 (2017).

[7] M. Dondi, T. Pascual e D. Paez, International Journal of Cardiovascular Sciences 31, 71 (2018).

[8] R.C. Costa, in XVII Encontro Nacional de Sociologia Industrial, das Organizações e do Trabalho (Setúbal, Portugal, 2018).

[9] https://www2.senado.leg.br/bdsf/bitstream/handle/id/70320/65.pdf.

[10] I. D'avilla, F. Pereira e I. Lages, Trab. educ. saúde 11, 319 (2013).

[11] F.C.A. Carvalho, Gestão do conhecimento (Pearson Brasil, São Paulo, 2012)

[12] L. Sheldon, The Multiplayer Classroom: Designing Coursework as a Game (Cengage Learning, Boston, 2012).

[13] M.C. Morosini, Revista de Educação da UFSM 40, 101 (2015).

[14] E.M. Lakatos e M.A. Marconi, Metodologia do trabalho científico (Editora Atlas, São Paulo, 2011).

[15] M.C.S. Minayo e O. Sanches, Cad. Saúde Públ. 9, 239 (1993).

[16] K.Y. Robert, Estudo de Caso: Planejamento e Métodos (Bookman Editora, Porto Alegre, 2015).

[17] https://www.google.com/forms/about/.

[18] https://phet.colorado.edu/pt_BR/.

[19] https://www.plickers.com.

[20] E. Mazur, Peer Instruction: A User's Manual (Prentice Hall Upper Saddle River, New Jersey, 1997).

[21] M.G. Muller, I.S. Araujo, E.A. Veit e J. Schell, Rev. Bras. Ensino Fís. 39, e3403 (2017). 